\title{
Para contribuir com a construção da dimensão político- pedagógica da socioeducação
}

\author{
To contribute to the construction of the policy and pedagogical dimension of social \\ education
}

\section{Zelimar Soares Bidarra*}

\begin{abstract}
Resumo:
O artigo trata de socializar alguns dos elementos que contribuíram para a organização e o desenvolvimento de um processo de reflexão sobre a política de socioeducação, empreendido a partir de um curso de especialização, cuja ênfase e desafio eram o de captar e interferir sobre as formas como aqueles que são sujeitos da implementação deste política, gestores e técnicos, estão assimilando e/ou recusando os parâmetros norteadores da ação estabelecidos pelo Sistema Nacional de Atendimento Socioeducativo (SINASE).
\end{abstract}

Palavras-chave: Estado. Política pública. Direitos humanos. Socioeducação.

\begin{abstract}
:
The article deals with some of the socializing elements that contributed to the organization and development of a process of reflection on the policy "socioeducação", undertaken from a specialization course, which was the focus and challenge of capturing and interfere in the ways those that are subject to the implementation of this policy, managers and technicians are assimilating and/or refusing the parameters guiding the action established by the National SocioEducational Services (SINASE).
\end{abstract}

Keywords: State. Public policy. Humans rights. "Socioeducação".

\section{Introdução}

Importa destacar que o presente texto tem uma forma de elaboração muito específica, qual seja: a de um relato de experiência que procura destacar alguns componentes de um trabalho realizado. Com esta advertência não se está antecipando qualquer pedido de desculpas, mas demarcando os limites desta narrativa na medida em

\footnotetext{
* Professora do Curso de Serviço Social e do Programa de Pós-Graduação em Desenvolvimento Regional e Agronegócio e da Universidade Estadual do Oeste do Paraná (UNIOESTE), campus de Toledo/Paraná. Foi coordenadora pedagógica do curso de especialização em Gestão de Centros de Socioeducação (PósCENSE). Líder do Grupo de Pesquisa e Defesa dos Direitos Humanos Fundamentais da Criança e do Adolescente (GPDDICA) e Membro do Grupo de Pesquisa GEMDEC/UNICAMP. E-mail: zelimar@yahoo.com.br
} 
que se propõe um relato sobre qual experiência de que se trata: a da operacionalização do curso de especialização, lato sensu, em Gestão de Centros de Sócio educação, empreendida na Universidade Estadual do Oeste do Paraná (UNIOESTE). ${ }^{1}$

Destaca-se que a UNIOESTE, desde o ano de 2004, por meio de docentes do Curso de Serviço Social e de atividades extensionistas, tem participado de processos continuados de formação de atores do Sistema de Garantia dos Direitos de crianças e de adolescentes pelos projetos conveniados e/ou contratados pelo Conselho Estadual dos Direitos da Criança e do Adolescente - Paraná (CEDCA). Nesse sentido, tem lastro o compromisso de tal grupo com a defesa e as formas de garantia dos direitos humanos fundamentais, essenciais para o exercício da cidadania, de crianças e adolescentes brasileiros.

O engajamento da UNIOESTE no desenvolvimento do Projeto deste Curso de Especialização ocorreu nos idos de 2007, quando a então Secretaria de Estado da Criança e da Juventude - Paraná (SECJ/PR) convidou dirigentes, membros das Pró-reitorias de PósGraduação, das instituições públicas UNIOESTE, UEL e UFPR, previamente escolhidas por tal Secretaria, a conhecerem e aderirem à proposta de ofertar, simultaneamente, cada uma para uma única turma, o referido Curso.

Confirmada a adesão da UNIOESTE, na sequência, internamente, fui indicada para integrar o Grupo de Trabalho $^{2}$ que fez a discussão do Projeto preliminar e as adequações necessárias para que este se configurasse como um curso de especialização. Na ocasião, todos os encontros de discussão do Grupo de Trabalho ocorreram nas dependências da SECJ/PR, e a versão final do Projeto do Curso de Especialização ficou pronta em dezembro de 2007.

Contudo, na medida em que o Projeto tinha a característica diferenciada de ser resultado da conjugação de esforços e de destinação de recursos dos governos estadual e federal (na época, por meio da Secretaria Especial de Direitos Humanos/SEDH), do Conselho Nacional dos Direitos da Criança e do Adolescente/CONANDA, da SECJ/PR, do

\footnotetext{
1 Para um conhecimento mais detalhado sobre o desenvolvimento e produtos construídos nesta experiência, ver o livro que registra este processo, intitulado Socioeducação: reflexões para a construção de um projeto coletivo de formação cidadã, organizado por Roesler e Bidarra (2011).

${ }^{2} \mathrm{Na}$ etapa de discussão, readequação e revisão do Projeto do Curso de Especialização o Grupo de Trabalho foi composto por membros da SECJ (Aline Fioravante e Leandro Müller), da Escola de Governo (Marta e Elisa), da UNIOESTE (Profa. Zelimar), da UEL (Profa. Vera Suguihiro) e da UFPR (Prof. Agostinho).
} 
Conselho Estadual dos Direitos da Criança e do Adolescente-Paraná/CEDCA, sua efetiva implementação demorou um tempo para acontecer. ${ }^{3}$ Somente tornou-se possível a partir do segundo semestre do ano de 2009.

Ressalta-se que a capacitação profissional dos gestores e dos técnicos é uma das condições primordiais para o alcance dos objetivos institucionais e, consequentemente, da efetividade da política pública desenvolvida, visando formar aptidões cognitivas e atitudinais alicerçadas em três eixos principais: o conhecimento, a interlocução e a retroalimentação pela avaliação institucional.

Dessa forma, a partir de uma perspectiva interdisciplinar, o Curso de Especialização colocou a região oeste do Paraná no circuito das unidades de formação de quadros técnicos capazes de atuar com qualidade teórica e competência técnica na formulação e operacionalização das políticas para a área da criança e juventude.

\section{A Dimensão Político-Pedagógica da Socioeducação}

No caso da UNIOESTE, como responsável pela coordenação pedagógica, cuidei da tramitação, aprovação e adequações de cronograma do Projeto do Curso de Especialização em Gestão de Centos de Sócio educação, que ocorreu entre os anos de 2008/2009. No entanto, as aulas foram iniciadas no mês de novembro de 2009.

Os leitores podem imaginar o que significa começar um curso de especialização quando se está no final de um ano letivo na universidade? Principalmente, quando o cronograma de execução estabeleceu o prazo máximo de treze meses para o desenvolvimento de todas as atividades acadêmicas, desde a execução de disciplinas, elaboração e apreciação de monografias por bancas, em sessões públicas? É possível supor o nível de tensão e desgaste físico, pois se estava diante do desafio de realizar aulas durante todos os sábados, entre fevereiro a dezembro de 2010? E estas sessões destinavam-se a um público de trabalhadores que vinha de jornada semanal de segunda a sexta-feira ou de jornadas por escalas (sistemas de plantões), para alguns dos quais, no período em questão, o único interstício de tempo para reposição de energias, convivência familiar e estudos passou a se resumir no dia de domingo.

\footnotetext{
${ }^{3}$ Neste transcurso de tempo, para a etapa da implementação, tivemos alterações no Grupo de Trabalho.
} 
Desta forma, este preâmbulo é necessário para demonstrar sob quais condições se desenvolveu este importante e inédito Projeto de um curso de especialização, empreendido simultaneamente por três universidades, com o objetivo de problematizar e apontar alternativas para o direcionamento da socioeducação, tanto no estado do Paraná, quanto no Brasil.

Contudo, iniciar esta empreitada não foi nada fácil e nem tranqüilo, pois, embora na UNIOESTE estejamos acostumados a propor e a realizar cursos de especialização, não contávamos com um corpo docente preparado para assumir a problematização de um tema tão específico como a socioeducação, e fundamentalmente sobre suas formas de gestão. Na realidade, sequer dispúnhamos de mais que três professores que estudavam e pesquisavam assuntos relativos à Infância e Juventude. É fato inconteste que mesmo após vinte e um anos de vigência do Estatuto da Criança e do Adolescente (Lei 8069/1990) "[...] o atendimento ao jovem que cometeu atos infracionais durante a adolescência é terra de ninguém, um terreno baldio entre as áreas da justiça, da segurança pública e da assistência social [...];" (ROSA, 2008, p. 13).

Mais intensivamente, nos últimos sete anos, desde a implementação da Política Nacional de Assistência Social (PNAS)/2004 que criou o Sistema Único de Assistência Social (SUAS) e da Norma Operacional Básica (NOB)/2005 - SUAS, o governo federal, por meio do financiamento da Assistência Social, e alguns governos estaduais, tem destinado recursos específicos para direcionar os enfoques das atuações profissionais e das instituições que são responsáveis por efetivarem o que temos definido como política de socioeducação.

No entanto, muitas das iniciativas se limitam ao espaço da interação com os adolescentes que transgrediram leis e/ou normas sociais. Logo, os conhecimentos e saberes movimentam-se num universo de circulação restrita e, não raras vezes, corroboram as formas de intervenção instituídas e assimiladas por determinados agentes governamentais. Neste sentido, estas experiências se contaminam, desde a origem, por uma orientação ideológica, o que enfraquece sua envergadura crítica.

Daí que para tornar a operacionalização do curso de especialização em Gestão de Centros de Sócio educação uma realidade, cujas aulas eram presenciais e tinham que estar pautadas por critérios de qualidade, relacionados com a capacidade de reflexão 
crítica dos alunos, foi necessário adotar uma estratégia de escolha do corpo docente para a qual o mais importante foi poder contar com aqueles que se dispuseram a estudar o tema da socioeducação antes de pensar o conteúdo da disciplina para a qual foram convidados. Outro dado relevante foi combinar a divisão das disciplinas entre dois docentes.

Assim, o debate sobre o tema e a forma de conectá-lo com assuntos específicos da área da gestão da socioeducação foram tratados pelos docentes desde o processo de elaboração do plano de ensino de cada disciplina. Acoplado a isto se tinha a interlocução com a Coordenação Pedagógica e com a Coordenação de Avaliação Institucional, para o caso das disciplinas que tinham as atividades práticas, no Curso da UNIOESTE, denominadas de "Vivências" (investigação/reflexão/proposição de alternativas), cuja finalidade era proceder etapas de avaliação institucional do processo socioeducativo, realizados pelos serviços/programas (em meio aberto e meio fechado) nos quais os alunos do Curso estavam lotados.

\begin{abstract}
Nesse contexto, a avaliação institucional é uma forma de capturar a prática em seu dinamismo, sem qualquer atitude antecipatória de pré-julgamento do sistema institucional existente dado que tem como seu objeto a rede de relações instituídas e instituintes que serve de matéria-prima à instauração e ao funcionamento das formas sociais que empiricamente conhecemos, tal como: família, Estado, socioeducação [...] (ALBUQUERQUE, 1978 apud ROESLER; BIDARRA, 2011, p. 422).
\end{abstract}

Pode-se afirmar que diante da inexistência de expertise no tema em tela, o que foi muito salutar, o caminho adotado foi o da conjugação coletiva de esforços, de docentes abertos para o novo, para se obter o maior sucesso possível. Pois, cada docente sabia que ao ministrar a disciplina ia se defrontar com um público que era hábil e sapiente a respeito de certo fazer cotidiano da prática socioeducativa. Afinal, o objetivo maior do curso de especialização era, justamente, tomar o senso comum, do cotidiano socioeducativo, e elevá-lo a um concreto pensado. Uma vez que:

O desafio da ação socioeducativa é harmonizar o conteúdo jurídicosancionatório e o ético-político inerente às medidas socioeducativas. A ação educativa pretende ser focada nas potencialidades e aspectos saudáveis dos adolescentes, independente do ato infracional praticado [...]. As medidas 
socioeducativas são sanções, mas, sobretudo, instrumentos pedagógicos [...] (JESUS, 2011, p. 2).

Destarte, é importante admitir que esta iniciativa de buscar se apropriar da prática cotidiana, socioeducativa, pelo ângulo da reflexão crítica não era uma seara comum para a maioria dos alunos e nem para alguns dos professores. Logo, este foi sempre um campo de tensão, profícuo e fecundo, no transcorrer das disciplinas. Dado que desde a primeira delas, Fundamentos de Gestão, era imprescindível localizar e refletir sobre quais premissas de gestão se pautava e deveríamos buscar referenciar a estruturação dos Programas (aberto e/ou fechado) de cumprimento de Medidas.

[...] Nesta perspectiva o enfoque histórico-crítico de socioeducação deve partir da análise das realidades sociais em que estão imersos os adolescentes e familiares, bem como a própria produção dos chamados atos infracionais e sua dimensão social, econômica e cultural (MENDONÇA, 2009, p. 7)

Neste tópico trabalhou-se com o referencial teórico que possibilita entender o papel e funções do Estado, da legislação social e das políticas públicas na ordem capitalista. Dado que se trata de um Estado de classes, sua forma de gerir as contradições, a conflituosidade e as desigualdades sociais, é sempre parcial e interessada, para proteger os interesses das elites que dominam os comandos das suas estruturas.

A política pública representa uma forma de direcionamento político-econômico da operacionalização das políticas sociais que, no capitalismo, sintetizam modos/arranjos para promover o acesso dos membros da classe trabalhadora aos bens de consumo coletivo que são criados a partir da riqueza social. Nesse sentido, as políticas públicas são originadas dos conflitos e das disputas por formas diferenciadas de repartição da riqueza social que estão inscritas nos projetos políticos societários.

$\mathrm{Na}$ atual conjuntura, tem predominado uma modalidade de projeto político ${ }^{4}$ que reivindica uma orientação gerencial para a implementação das políticas públicas. Tal orientação ganha repercussão quando, os recursos de que dispõe são mobilizados para

\footnotetext{
${ }^{4}$ A noção de projeto político indica a necessidade de se prestar atenção às diferentes expectativas que as pessoas têm sobre a vida em sociedade. Nessas expectativas, estão creditados os valores tidos como significativos para as experiências coletivas, bem como os princípios orientadores das ações políticas dos grupos sociais. Uma forma de se tornarem perceptíveis as trocas sociais é mediante as disputas de projetos políticos.
} 
atender a uma lógica de descentralização e um tipo de participação política "anexada", aquela que costuma se resumir no "fazer número", é plateia para uma proposta previamente selecionada.

Em geral, essa plateia não externaliza qualquer manifestação e nem assume posturas contrárias às das forças dominantes ou dos dirigentes. Essa forma de participação parece oportuna para manter a centralização do poder e para reforçar as proposições que interessam e correspondem às expectativas daqueles que estão no comando e representam os interesses do grupo político dominante. Foi justamente contra essa retórica que se enfatizou a importância da reflexão sobre o que significa fazer a Gestão, referenciada pelos direitos humanos, na área da socioeducação.

$\mathrm{Na}$ sequência, deparou-se com a dificuldade de trabalhar com o conteúdo da avaliação/análise institucional, não por dispor de conhecimento teórico e prático sobre este assunto, mas porque a premissa fundante da avaliação/análise institucional é tomar como ponto de partida o conceito/definição, categoria, isto é, aquilo que dá a delimitação do objeto/instituição que se vai avaliar/analisar.

Neste caso, é possível afirmar que uma importante descoberta foi a da fragilidade, insuficiência, ou mesmo, imprecisão do que se entende por socioeducação, nos documentos que, até então, tem nos servido como fonte de consulta e de referência, tais como: Sistema Nacional de Atendimento Socioeducativo - SINASE (BRASIL, 2006) e Cadernos do IASP (PARANÁ, 2007).

No SINASE (BRASIL, 2006, p. 46), vê-se que o conceito de socioeducação gravita em torno da seguinte compreensão:

O adolescente deve ser alvo de um conjunto de ações socioeducativas que contribua na sua formação, de modo a que venha ser um cidadão autônomo e solidário, capaz de se relacionar melhor consigo mesmo, com os outros e com tudo que integra a sua circunstância e sem reincidir na prática de atos infracionais.

Nos Cadernos do IASP tem-se que:

[...] O conceito de socioeducação ou educação social, no entanto, destaca e privilegia o aprendizado para o convívio social e para o exercício da cidadania [...] Deve-se compreender que educação social é educar para o coletivo, no 
coletivo, com o coletivo. É uma tarefa que pressupõe um projeto social compartilhado [...](PARANÁ, 2007, p. 19

Nas definições acima se vê o acento para o componente educativo da prática em tela. Contudo, no extrato do SINASE fica evidente que é uma prática para aqueles sujeitos circunscritos nos liames da autoria do ato infracional. Ainda que mediante a tal prática se vislumbre uma mudança de projeto de vida para estes indivíduos, assume-se como imprescindível "[...] propiciar aos adolescentes o acesso a direitos e às oportunidades de superação de sua situação de exclusão, de ressignificação de valores, bem como o acesso à formação de valores para a participação na vida social" (BRASIL, 2006, p. 46).

Na exegese dos Cadernos do IASP esta apresentada e enfatizada como uma modalidade de educação política que se pretende para qualquer sujeito no âmbito de uma sociedade democrática, quando se almeja torná-lo protagonista de sua própria história. Pois,

A socioeducação como prática pedagógica propõe objetivos e critérios metodológicos próprios de um trabalho social reflexivo, crítico e construtivo, mediante processos educativos orientados à transformação das circunstâncias que limitam à integração social [...] (PARANÁ, 2007, p. 19)

Afirma-se que a tensão entre essas duas orientações conceituais estiveram presentes em todo o desenrolar do Curso de Especialização, ora o debate se enfeixava na defesa de um caráter mais restritivo e ora tendia para um caráter mais abrangente de prática socioeducativa. Isto pode ser explicado pelo seguinte fator, para alguns dos profissionais e dos autores estudados o "campo" da socioeducação deve ser tão especializado e gestionado por técnicos tão habilitados para o tema que não permite a interferência daqueles que não dominam os códigos da comunicação da área.

Logo, no espectro desta compreensão, vê-se esvaziar o sentido e a ideia da presença e da participação de uma comunidade socioeducativa, que na premissa do SINASE (BRASIL, 2006) é formada pelos técnicos da área, os gestores, as famílias, os adolescentes e os representantes dos serviços da rede de atendimento. Um entendimento stricto sensu de organização de atendimento socioeducativo não está apto a incorporar e dialogar com esta pluralidade de sujeitos, pois, lamentavelmente, crê que a pluralidade compromete a identificação da fonte de enunciação do comando e das 
ordens, isto é, "dilui a autoridade!". Interessante observar que esta postura se coaduna com uma concepção política de gestão, de cunho conservador, que defende o primado da tecnocracia como requisito da qualificação do serviço prestado.

A prerrogativa política de compartilhar a definição e a orientação dos programas, projetos e serviços concernentes às funções precípuas das políticas públicas, nem sempre tem recebido a devida atenção por parte dos gestores dessas mesmas políticas, sejam eles: dirigentes, técnicos das secretarias afetas ou mesmo conselheiros gestores de políticas. Assim, muitas vezes, um conselho termina por se afastar e não assumir aquilo que é de sua competência.

Com isso, muitas das atribuições de um conselho permanecem sendo, erroneamente, percebidas e difundidas como competências privativas dos técnicos dos órgãos governamentais e das entidades prestadoras de serviços. Ora, isso alimenta os "discursos racionalizadores", que estão à procura de um argumento que lhes permita reafirmar a habilidade da tecnocracia para lidar com os ditos aspectos técnicos.

Em face disto, foi inevitável que os confrontos políticos e ideológicos tergiversassem os estudos e reflexões durante a realização do Curso, pois, cada vez mais, éramos provocados a deslizar e partilhar da convicção propostas pelos estudiosos que tem uma perspectiva política mais democrática e progressista, de que para fazer a socioeducação no Brasil é fundamental extrapolar os limites institucionais dos Programas de Cumprimento de Medidas, seja em meio aberto ou fechado se com ela se pretende redesenhar e reescrever os projetos de vida desses sujeitos. Para isso, é essencial que a educação a Ihes ser ofertada deve decorrer de um "[...] ato de produzir, direta e intencionalmente, em cada indivíduo singular, a humanidade que é produzida histórica e coletivamente pelo conjunto dos homens" (MENDONÇA, 2009, p. 7).

Transformar a concepção e a orientação dos atendimentos prestados aos adolescentes sentenciados por autoria de ato infracional não é algo fácil. Provocar o deslocamento de uma arraigada cultura institucional de caráter repressivo e discriminatório para uma cultura política e institucional de caráter educativo pautada pelos referenciais dos direitos humanos requer confrontar-se com práticas instituídas pelos arcaísmos e autoritarismo social, tão peculiar à cultura política das elites brasileiras que ao longo de décadas sustenta seu entendimento discricionário para com as crianças e 
adolescentes das camadas populares e suas experiências de exclusão e privação de toda ordem.

Um traço peculiar do autoritarismo social brasileiro consiste em imprimir às relações sociais uma forma de sociabilidade construída a partir do silêncio dos dominados, o qual é forjado, cotidianamente, por meio da desqualificação e, no extremo do espetáculo, da ridicularização dos discursos, dos códigos de interação e de pronunciamento dos "sujeitos falantes".

A reprodução de um contingente expressivo de "não cidadãos" facilita a conservação das relações de submissão, refletindo um problema histórico dessa sociedade: a dificuldade de forjar um projeto de sociedade que objetive a transformação radical das relações sociais. Por isso, ela tem sido signatária de um tipo de experiência democrática que estende as desigualdades e a apartação social como medidas necessárias à acumulação de capital.

Para acreditar e insistir na possibilidade da transformação do campo institucional da socioeducação é preciso admitir, como ponto de partida, que:

[...] as mudanças de métodos, conteúdos e de gestões requeridas nas políticas públicas referentes às medidas sócio-educativas contempladas no Estatuto ainda não foram efetivadas, pois na prática continuamos a ver a presença absoluta da lógica menorista. De fato, o sistema de execução das medidas sócio-educativas passou apenas por transformações superficiais no que se refere à efetivação da lógica proposta, de modo que as práticas executadas pelos operadores do direito da Criança e do Adolescente são absolutamente distantes dos artigos e princípios legais prescritos no Estatuto (ROSA, 2008, p. 13).

Entretanto, há um fato do qual não se pode abrir mão, qual seja, um atendimento socioeducativo em condições de preservação da dignidade é um direito fundamental do adolescente sentenciado por ato infracional (BRASIL, 1990). E este atendimento deve lhe permitir reescrever o sentido de sua vida, isto é, oportunizar-lhe a elaboração de

[...] um projeto de vida responsável, [o qual] fundamentalmente [advém de] um processo de conscientização do próprio jovem acerca de usas capacidades e potencialidades - isto é, sua educação. Mas, também, é fundamentalmente um estímulo para a própria (re) organização de sua vida - enfim, de suas estruturas cognitivas - ou seja, um processo pedagógico que lhe proporcione uma intersubjetividade racional digna, inclusive, para que possa tornar mais 
proveitosas as relações interpessoais, mediante a compreensão adequada das regras que presidem toda relação social (RAMIDOFF, 2011, p. 104).

O Estatuto assegura ao adolescente autor da infração a preservação do seu direito à dignidade, diante de qualquer circunstância, no entanto, o usufruto deste direito ainda é carente de materialidade, visto que a efetivação da socioeducação é atravessada por ambiguidades, ora se reafirma a necessidade da intensificação da punição e da repressão, ora se pretende uma educação social para a cidadania.

Diante disso, inúmeros são os desafios para que as práticas políticas e profissionais responsáveis pela organização e condução do cumprimento das Medidas Socioeducativas, que mais amplamente devemos denominar como campo da socioeducação, indiquem novos caminhos, novas oportunidades e a germinação de formas de vida e de subsistência aportadas pelos direitos da cidadania.

Essa é a perspectiva socioeducativa que se vislumbra como uma promessa de educação para a cidadania, a qual se compromete com o reconhecimento do adolescente como pessoa em situação peculiar de desenvolvimento, sujeito de direitos e de responsabilidades, bem como pertencente a uma coletividade. A ele deve ser dada a condição e o apoio, a partir de instrumentos legaisinstitucionais, para cumprir a medida socioeducativa em condições respeitosas e dignas, que lhe permitam o fortalecimento dos vínculos familiares e comunitários (ROESLER; BIDARRA, 2011, p. 15).

No entanto, para que isto seja uma realidade, não se pode prescindir do preceito constitucional (1988) de que a gestão da vida socioinstitucional no Brasil deve pautar-se pela gestão democrática e participativa, que entrelaça em compromissos ético-públicos as forças sociais organizadas advindas da sociedade civil e do aparato governamental.

\section{Considerações Finais}

Na Constituição de 1988, encontram-se os aparatos que garantem a disseminação da demanda participativa. Nela estão confirmados alguns dos anseios e dos projetos das forças sociais que, durante o momento constituinte, puseram na pauta e inauguraram uma intensa disputa pela inadiável participação e socialização da política, isto é, o compartilhamento do poder estatal com as organizações da sociedade civil. Essas 
demandas expressam o compromisso com a continuidade do processo de construção democrática da sociedade brasileira (BRASIL, 1988).

Por isso, os atores do Sistema de Garantia dos Direitos precisam manter a aposta política na construção de espaços públicos e democráticos para tematizarem a perspectiva da Proteção Integral devida ao adolescente autor da infração. Ao mesmo tempo, eles não podem perder de vista os adversários políticos, aqueles com quem têm que disputar a partilha e a construção de projetos para a construção e consolidação de uma política de socioeducação referenciada pela garantia dos direitos humanos.

\begin{abstract}
Pois a política é uma práxis, mas, é sobretudo uma aposta e uma perspectiva: a de que se deve dar respostas às demandas e aos valores socialmente instituídos, tendo em vista a fixação de um horizonte de sentido comum. A perspectiva e a aposta da política implicam, portanto, a capacidade de discernir as questões fundamentais da existência coletiva, mantendo vivo na agenda o problema de saber quem somos, por que estamos juntos e que objetivos desejamos alcançar. Exatamente por isso a política confunde-se sempre mais com o espaço público - e de modo particular com o espaço público democrático - ou seja, com aquele território onde se torna possível representar e transformar interesses, afetos e paixões (NOGUEIRA, 1998, p. 18-19, grifo do autor).
\end{abstract}

Assim, para que haja uma política pública de socioeducação de caráter democrático, é necessário garantir a existência dos espaços onde possam alcançar visibilidade e se processarem as disputas entre os diferentes interesses e projetos construídos pelos segmentos sociais que militam e atuam na área.

Os espaços públicos são os canais privilegiados para os encontros, a explicitação, as disputas e as negociações entre aqueles que defendem posições diferenciadas quanto ao nível de partilha da riqueza social transferidas pelas políticas públicas. Nesse sentido, problematizar o conjunto das implicações que são relativas à noção de espaço público é, para Telles, ${ }^{5}$ comprometer-se com as lutas políticas do nosso tempo histórico que tentam desenhar uma perspectiva de futuro para a incompleta democracia brasileira.

Assim, não é decisivo se o espaço público está localizado no âmbito das relações da sociedade civil ou do aparato estatal. Em qualquer um desses, a constituição do espaço público tem como pré-requisito o confronto entre as relações instituídas, as quais

\footnotetext{
${ }^{5}$ Perspectiva enunciada por Vera da Silva Telles na mesa redonda "Sociedade Civil, Esfera Pública e Gestão Participativa no Brasil”, em 11/05/2001, no auditório do IFCH-Unicamp.
} 
sustentam uma estrutura elitista de reprodução das relações de poder e de domínio. Desse modo, a constituição democrática desse espaço também significa a redefinição das relações sobre outras bases e outros critérios.

\section{Referências}

BRASIL. Constituição da República Federativa do Brasil de 1988. Disponível em: <http://www.planalto.gov.br/ccivil_03/constituicao/constitui\%C3\%A7ao.htm>. Acesso em: 14 de dezembro de 2011.

BRASIL. Lei no 8.069, de 13 de julho de 1990. Texto compilado Dispõe sobre o Estatuto da Criança e do Adolescente e dá outras providências. Disponível em: <http://www.planalto.gov.br/ccivil_03/leis/L8069.htm>. Acesso em: 14 de dezembro de 2011.

BRASIL. Secretaria Especial de Direitos Humanos (SEDH). Sistema Nacional de Atendimento Socioeducativo - SINASE. Brasília: CONANDA, 2006.

INSTITUTO DE AÇÃO SOCIAL DO PARANÁ - IASP. Gestão de centros de socioeducação. Curitiba, 2007. (Cadernos do IASP).

JESUS, V. C. P. Educação e trabalho na socioeducação: possibilidades e desafios. 2011. Disponível em:

<http://histedbr.fae.unicamp.br/acer_histedbr/seminario/seminario8/files>. Acesso em: 16 de dezembro de 2011.

MENDONÇA, A. Análise das tendências pedagógicas na educação e no SINASE. Brasília: Sistema Nacional de Atendimento Socioeducativo, 2009. (mimeo).

. As possibilidades da política: idéias para a reforma democrática do Estado. São Paulo: Paz e Terra, 1998.

PARANA. Cadernos do IASP: Gestão de centros de socioeducação. Instituto de Ação Social do Paraná - IASP Curitiba, 2007.

RAMIDOFF, M. L. Lições de direito da criança e do adolescente: ato infracional e medidas socioeducativas. 3. ed. Curitiba: Juruá, 2011.

ROESLER, M. R. B.; BIDARRA, Z. S. (Org.). Socioeducação: reflexões para a construção de um projeto coletivo de formação cidadã. Cascavel: EDUNIOESTE, 2011.

ROSA, Pablo Ornelas. De infratores à redutores de danos: experiências com jovens que cometeram atos infracionais durante a adolescência em Santa Catarina. 2008. Disponível em: <www.neip.info/html/objects/_downloadblob.php?cod_blob=693>. Acesso em: 16 de dezembro de 2011.

Recebido em: 16/12/2011

Aprovado em: 30/12/2011 